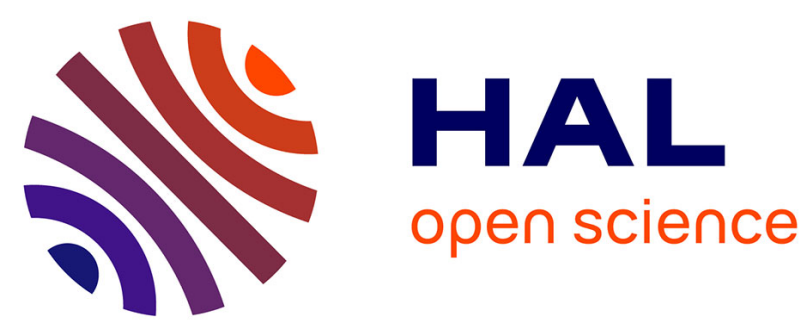

\title{
Central nervous system infections in a tropical area: Influence of emerging and rare infections
}

Hugo Chaumont, E. Roze, B Tressières, Françoise Lazarini, Annie Lannuzel

\section{To cite this version:}

Hugo Chaumont, E. Roze, B Tressières, Françoise Lazarini, Annie Lannuzel. Central nervous system infections in a tropical area: Influence of emerging and rare infections. European Journal of Neurology, 2020, Online ahead of print, 10.1111/ENE.14422 . pasteur-02888008

\section{HAL Id: pasteur-02888008 \\ https://hal-pasteur.archives-ouvertes.fr/pasteur-02888008}

Submitted on 2 Jul 2020

HAL is a multi-disciplinary open access archive for the deposit and dissemination of scientific research documents, whether they are published or not. The documents may come from teaching and research institutions in France or abroad, or from public or private research centers.
L'archive ouverte pluridisciplinaire HAL, est destinée au dépôt et à la diffusion de documents scientifiques de niveau recherche, publiés ou non, émanant des établissements d'enseignement et de recherche français ou étrangers, des laboratoires publics ou privés.

\section{(1)(1) $\$(0)$}

Distributed under a Creative Commons Attribution - NonCommercial - ShareAlikel 4.0 
DR. HUGO CHAUMONT (Orcid ID : 0000-0002-1585-7512)

DR. ANNIE LANNUZEL (Orcid ID : 0000-0003-4084-8674)

Article type : Original Article

\title{
Central nervous system infections in a tropical area: Influence of emerging and rare infections
}

\author{
H. Chaumonta,b,c, E. Roze ${ }^{c, d}$, B. Tressières ${ }^{e}, F$. Lazarinif $^{f}$ and A. Lannuzela,b,c,e
}

${ }^{a}$ Centre Hospitalier Universitaire de la Guadeloupe, Service de Neurologie, Pointe-àPitre/Abymes, French West Indies, France

${ }^{b}$ Faculté de Médecine de l'université des Antilles, French West Indies, Pointe-à-Pitre, France

cFaculté de Médecine de Sorbonne Université, Institut National de la Santé et de la Recherche Médicale, U 1127, CNRS, Unité Mixte de Recherche (UMR) 7225, Institut du Cerveau et de la Moelle épinière, ICM, Paris, France

dAP-HP, Hôpital de la Pitié-Salpêtrière, Département de Neurologie, Paris, France

e Centre d'investigation Clinique Antilles Guyane, Inserm CIC 1424, Pointe-à-Pitre, France fInstitut Pasteur, Perception and Memory Unit, Centre National de la Recherche Scientifique, Unité Mixte de Recherche 3571, Paris, France

Corresponding author: Hugo Chaumont, MD, Department of Neurology, University Hospital of Guadeloupe, 97139, Pointe-à-Pitre/Abymes, French West Indies, France. Tel.: +590 590891 430; fax: +590 590891 431; e-mail: hugo.chaumont@chu-guadeloupe.fr

Running title: Infectious encephalitis in Guadeloupe

Keywords: encephalitis; transverse myelitis; zika; leptospirosis; Guadeloupe.

Total word count: 4488

Main Text: 2925

Abstract: 245

This article has been accepted for publication and undergone full peer review but has not been through the copyediting, typesetting, pagination and proofreading process, which may lead to differences between this version and the Version of Record. Please cite this article as doi: 10.1111/ENE.14422

This article is protected by copyright. All rights reserved 


\section{Disclosure of conflict of interests}

H. Chaumont: received travel grants from PEPS development, Roche and Pfizer. E. Roze: served on scientific advisory boards for Orkyn, Aguettant, Merz-Pharma; received honoraria for speeches from Orkyn, Aguettant, Merz-Pharma, Medday-Pharma, Everpharma, International Parkinson and Movement disorders Society; received research support from Merz-Pharma, Orkyn, Aguettant, Elivie, Ipsen, Everpharma, Fondation Desmarest, AMADYS, Fonds de Dotation Brou de Laurière, Agence Nationale de la Recherche; received travel grant from Vitalair, PEPS development, Aguettant, Merz-Pharma, Ipsen, Merck, Orkyn, Elivie, Adelia Medical, Dystonia Medical Research Foundation, International Parkinson and Movement disorders Society, European Academy of Neurology, International Association of Parkinsonism and Related Disorders. A. Lannuzel: received research support from France Parkinson, PSP France, Agence Nationale de la Recherche, Fonds européen de développement regional, French Ministry of Health, University Hospital of Guadeloupe; received honoraria from Association des Neurologues du Québec and travel grants from Vitalair, PEPS development, Merz-Pharma, International Parkinson and Movement disorders Society. B. Tressières and F. Lazarini have nothing to declare. 


\begin{abstract}
Background and purpose: The frequency of infectious encephalitis and the distribution of causative pathogens in the tropical areas are poorly known and may be influenced by emerging and rare infections. The aim was to characterize a large series of acute infectious encephalitis and myelitis in immunocompetent patients from the Caribbean island of Guadeloupe identifying clinical, biological and radiological features according to pathogens.
\end{abstract}

Methods: Using a hospital database, we retrospectively collected detailed information on a comprehensive series of immunocompetent patients with acute infectious myelitis and encephalitis over the 2012-2018 period.

Results: From 259 suspected cases with acute central nervous system (CNS) infection, we included 171 cases for analysis, comprising 141 encephalitis, 22 myelitis, and eight encephalomyelitis. The annual incidence peaked at 15.0/100 000 during the Zika 2016 outbreak. Children accounted for $22.2 \%$ of cases. Eight adults died during hospital stay, all encephalitis. Seventeen infectious agents, two of which had never been described in Guadeloupe so far, were identified in 101 cases $(59.1 \%)$, including 35 confirmed cases (34.7\%), 48 probable cases (47.5\%), 15 possible cases (14.9\%) and three clinical cases (3.0\%). The most frequent etiologic agents were zika virus in 23 cases (13.5\%), herpes simplex in $12(7.0 \%)$, varicella-zoster virus in $11(6.4 \%)$, dengue virus in $11(6.4 \%)$ and leptospirosis in $11(6.4 \%)$.

Conclusions: Zika outbreak had a major influence on the annual incidence of acute CNS infection. Acute neuroleptospirosis is over-represented in our series. Further efforts are mandatory to develop new diagnostic tools for pathogen profiling.

\title{
Introduction
}

The incidence of infectious encephalitis in temperate countries in immunocompetent subjects is estimated at 1.9 to 4.3 cases per 100,000 inhabitants per year $(1,2)$. In North America and Europe, viruses of the Herpes group (Herpes Simplex (HSV), Varicella-zoster (VZV) and EpsteinBarr virus (EBV)) are the first cause of infectious encephalitis accounting for 25 to $32 \%$ of the cases (3-5). In tropical area, prospective epidemiological studies report a higher incidence of $14 / 100000$ in Thailand and 50/100 000 in India (6,7). The distribution of causative pathogens

This article is protected by copyright. All rights reserved 
differs from that observed in Europe or North America. Arboviruses may represent up to $28 \%$ of cases (6). The causative infectious agent remains undetermined in most cases (ranging from $40 \%$ to $50 \%$ in large prospective studies) $(3,4)$. Causes and incidence of acute infectious myelitis are poorly studied and there is no large series of patients.

To characterize the full spectrum of infectious agents causing encephalitis, myelitis and their outcome, we retrospectively collected detailed information on a series of consecutive patients with acute CNS infection in the Caribbean island of Guadeloupe over a seven-year period (20122018).

\section{Methods}

\section{Patients and study design}

We extracted all cases registered as infectious encephalitis or myelitis from the database of the University Hospital of Guadeloupe (UHG) between January 2012 and December 2018.

Patients were seen in the departments of Neurology, Infectiology, Intensive care, Pediatrics, and General Medicine in the UHG, the only tertiary center in an Archipelago counting 420000 inhabitants. In 2016 during the last population census, the age distribution in the Guadeloupean population was: 0-14 years old (21.5\%); $15-29$ years old (17.4\%); 30-44 years old (19.9\%); $45-59$ years old $(21.5 \%) ; 60-74(13.1 \%), 75$ years old and more $(6.6 \%)$.

\section{Standard protocol approvals, registrations, and patient consents}

According to the French regulation, the retrospective use of our hospital database was approved by the National Commission of Information Technology and Civil Liberties (declaration number 2171956 v 0). The local IRB ("EREGIN", University Hospital of Guadeloupe), reviewed and approved the study protocol. The study was classified as an observational study according to the rules of the French regulation. As local ethic committee did not require to get written consent for this observational study, oral informed consent was obtained from all participants after providing them written explanations, and the study was performed according to the approved protocol.

\section{Diagnosis of encephalitis and myelitis}

We included patients aged at least one month with acute manifestations of encephalitis or myelitis persisting over $24 \mathrm{~h}$, and no other diagnosis than infection. For encephalitis, at least one major criterion and two minor criteria were necessary. Major criteria were: consciousness or vigilance disorder, behavioral disorder, one or several partial or generalized seizures non attributable to a pre-existing seizure disorder, a recently appeared focal neurological symptom. 
Minor criteria were: a temperature over $37.8^{\circ} \mathrm{C}$, a biological anomaly of the cerebrospinal fluid (CSF) (CSF leukocyte count $\geq 4 \times 10^{6}$ cells $/ \mathrm{l}$, CSF protein concentration $\geq 40 \mathrm{mg} / \mathrm{dl}$ ), a cerebral imaging suggesting a recently appeared encephalitis, an anomaly evoking encephalitis detected through electroencephalogram (EEG) and non-attributable to another pathology. EEG abnormalities ranged from nonspecific generalized slowing to distinctive patterns suggestive of specific entities, including repetitive sharp wave complexes over the temporal lobes or periodic lateralizing epileptiform discharges or bilateral synchronous periodic sharp and slow waves. For acute myelitis, patients had i) sensory/motor manifestations or dysautonomia attributable to the spinal cord, ii) a signal abnormality or contrast enhancement on spinal cord MRI or an abnormal CSF (leukocyte count $\geq 4 \times 10^{6}$ cells/l or a protein level in CSF $\geq 40 \mathrm{mg} / \mathrm{dl}$ ) was required, iii) progression to nadir of under 21 days following the onset of symptoms.

The exclusion criteria were positive human immunodeficiency virus (HIV) status; meningitis with no argument supporting cerebral parenchyma damage; acute pyogenic meningoencephalitis (classically excluded in series of infectious encephalitis); cerebral, brainstem, cerebellar abscesses; intramedullary and epidural abscess of the spinal cord.

The patients were listed as "confirmed" when the pathogenic agent or its genome was found inside the CSF, or if there was a seroconversion inside the CSF. The affection was "probable" if the agent or its genome was found outside the CSF, or if there was a seroconversion outside the CSF, or a high single immunoglobulin $\mathrm{M}(\operatorname{lgM})$ measure was found inside the CSF. It was "possible" if a high single immunoglobulin M (IgM) measure was found outside the CSF. It was of high clinical presumption, referred to as "clinical cases" if massive clinical arguments in favor of an infectious etiology were retained, without biological proof. The remaining cases were classified as "undetermined".

Nineteen neurozika patients were comprehensively described in a previous publication (8).

\section{Statistical analyses}

Quantitative variables were summarized as median with interquartile range (IQR) and compared across groups using Mann-Whitney non-parametric test. Categorical data were expressed as percentages and compared between groups using Chi-square test or Fisher exact test, depending on the sample size. For each year of the study period, the incidence rates were calculated by dividing the number of incident cases per year by the number of inhabitants in Guadeloupe estimated by INSEE (Institut National de la Statistique et des Etudes Economiques). The 95\% confidence intervals $(\mathrm{Cl})$ were calculated assuming a Poisson distribution. Odds-Ratios (OR) and their 95\% confidence intervals were calculated using logistic regressions to identify clinical and biological factors associated with the occurrence of zika virus (ZIKV) and dengue 
virus (DENV) encephalitis in adult population ( $\geq 16$ years old) (crude Odds-Ratios) and the need for mechanical ventilation during hospitalization (adjusted Odds-Ratios). Statistical analyses were performed using SPSS (v. 21, IBM SPSS Statistics, Chicago, IL); significance was considered at the $5 \%$ level.

\section{Data availability}

Some data will be made available from the corresponding author, upon reasonable request. The data are not publicly available because they contain information that could compromise the privacy of our patients.

\section{Results}

\section{Population}

We included for analysis 171 patients presenting an acute infectious myelitis/encephalitis in 2012-2018 (Fig. 1).

The annual incidence peaked at 15.0/100 000 in 2016 during the Zika outbreak (Fig. 2). Zika virus (ZIKV) infection, but neither dengue virus (DENV) nor chikungunya virus (CHIKV) outbreak had a significant influence on incidence rate of infectious encephalitis or myelitis.

General characteristics of the patients are shown in Table S1. Children accounted for $22.2 \%$ of cases. Encephalitis were more frequent in men (59.6\%), women having more myelitis (68\%) and encephalomyelitis $(75 \%)$. Half of the patients with encephalitis had a normal brain MRI.

\section{Etiology}

Although acute CNS infection was suspected in all cases included for analysis, infectious agents were identified reliably in only 101 cases (59\%). In 35 of them (34.7\%) an infectious agent was detected in the CSF (confirmed cases). Forty-eight patients (47.5\%) were probable cases (22 with identified pathogen out of CSF or 26 with seroconversion in the serum). Possible cases or clinical cases represented respectively $14.9 \%(n=15)$ and $3.0 \%(n=3)$.

The infectious causative agent was a virus in 75 patients (74.3\%), a bacterium in 21 $(20.8 \%)$, a fungus in $4(4.0 \%)$ and a parasite in one (1\%). Seventeen different etiologic agents were identified (Table S2). The five most frequent were ZIKV in 23 cases (13.5\%), HSV in 12 (7.0\%), VZV in 11 (6.4\%), DENV in 11 (6.4\%) and leptospirosis (LEPT) in 11 (6.4\%) (Table S3). VZV was the most frequent pathogen in children (13.2\%). The 12 other infectious agents in the remaining 33 cases $(19.3 \%)$ were: enterovirus (EV, $n=8)$, Mycoplasma pneumoniae $(n=5)$, Syphilis $(n=4)$, CHIKV $(n=3)$, Cryptococcus neoformans $(n=3)$, EBV $(n=3)$, cytomegalovirus 
(CMV, $\mathrm{n}=2)$, Angiostrongilus cantonensis $(\mathrm{n}=1)$, Aspergillus sp $(\mathrm{n}=1)$, human influenza A virus $(\mathrm{n}=1)$, human T-Cell leukemia virus $(\mathrm{HTLV}, \mathrm{n}=1)$ and Listeria monocytogenes $(\mathrm{n}=1)$.

\section{Arboviruses}

A flavivirus (ZIKV, DENV) or an alphavirus (CHIKV) was involved in 37 cases $(21.6 \%)$. CHIKV was responsible for two myelitis (Fig. 3A) and one encephalitis, DENV for two myelitis (Fig. 3B), eight encephalitis, two of which resulting in a fatal outcome (Fig. $3 \mathrm{C}$ ), and one encephalomyelitis. ZIKV was responsible for 14 encephalitis, one of them fatal, six myelitis and three encephalomyelitis.

Spinal location causing myelitis or encephalomyelitis was more frequent in patients with flavivirus infection (ZIKV and DENV) than those in the herpes virus group (HSV/VZV/EBV) $(P=$ $0.035)$ (Table $S 4)$. The other factors associated with flavivirus infection versus herpes virus infection were: female sex $(P=0.037)$, rash $(P=0.025)$, arthritis $(P<0.001)$, abdominal pain $(P=$ 0.031). Inversely low natremia $(P=0.010)$ and altered consciousness $(P=0.007)$ were predominantly associated to herpes virus infections (Table S4). Rash (OR 20.0, 95\% Cl 6.33, 66.20), arthritis (OR 27.38, 95\% Cl 7.86, 95.35), conjunctivitis (OR 33.69, 95\% Cl 3.87, 293.10), absence of altered consciousness (OR $2.70,95 \% \mathrm{Cl} 1.02,7.14)$ were associated with ZIKV CNS infection (Table S5).

\section{Leptospirosis}

Leptospirosis was identified in 11 adult cases (6.4\%), including ten men. Detailed characteristics of these patients are shown in Table S6. Diagnosis was probable in eight cases, possible in two cases and one patient was a "clinical case". The median age was 59 (IQR, 56-62). Three patients, all men, were employed as farmers or working with animals. Imaging showed an acute stroke in two patients (patient 6 and 10), and a transverse myelitis in one (patient 11, Fig. 3D). The factors associated with neuroleptospirosis (Table S7) were male sex (OR 9.44, 95\% Cl 1.15, 77.78), icterus (OR 4.41, 95\% Cl 1.91, $\infty$ ), abdominal pain (OR 5.14, 95\% Cl 1.20, 22.05), breathing dysfunctions (OR 4.43, 95\% Cl 1.06, 18.55), AST >120 U/I (OR 12.38, 95\% Cl 2.29, 66.95), ALT >103 U/I (OR 28.87, 95\% Cl 2.93, $\infty)$, creatinine >106 $\mu \mathrm{mol} / \mathrm{l}$ (OR 8.00, 95\% Cl 1.90, 33.63 ) and platelets $<150 \times 10^{9}$ cells/l (OR $\left.7.08,95 \% \mathrm{Cl} 1.81,27.67\right)$.

\section{Rare etiologies - Clinical features and management}


A diabetic 85 years old woman was admitted with confusion, aphasia, altered level of consciousness, dysexecutive syndrome, behavioral disorders and cerebellar syndrome. Brain MRI showed diffuse bilateral abnormalities (Fig. 3E). CSF analysis showed white cell count at $4 \times$ $10^{6} \mathrm{cells} / \mathrm{l}$, protein level was $104 \mathrm{mg} / \mathrm{dl}$, and glucose level was normal at $3.1 \mathrm{mmol} / \mathrm{l}$. Aspergillus $s p$. was detected by RT-PCR in the CSF. Aphasia and altered level of consciousness were slowly improved after introduction of Voriconazole IV. There was no post-discharge follow-up.

A 10 months old boy was admitted with altered consciousness, urinary retention, lower limb and back pain, flaccid tetraplegia with areflexia. Two days before he had presented rash, asthenia, anorexia, limbs edema and fever. Spinal MRI showed cervical and lumbar spinal cord abnormalities (Fig. 3F). CSF showed a meningitis with white cell count at $280 \times 10^{6}$ cells/l (lymphocytes 63\%, eosinophils 30\%, macrophages 4\%, PNn 3\%), protein level at $111 \mathrm{mg} / \mathrm{dl}$ and low glucose at $1.0 \mathrm{mmol} / \mathrm{l}$. Angiostrongilus cantonensis RT-PCR was positive in CSF. Albendazole IV was combined with corticosteroid therapy and patient slowly improved. He has gait disorder sequelae.

\section{Patient management, outcome and risk factors}

Duration of the stay in hospital was shorter in children (8 days, IQR, 4-11) than in adults (14 days, IQR, 9-23, $P<0.001)$. Fifty-seven patients (33.3\%) including three children were admitted in intensive care unit (Table S1). Mechanical ventilation was required in 35 cases, including two children. In multivariate analysis, altered level of consciousness (OR 7.64, 95\% Cl 2.06, 28.34), seizures (OR 4.11, 95\% Cl 1.65, 10.20), and abnormal MRI (OR 2.68, 95\% Cl 1.08, 6.65) were risk factors of mechanical ventilation (Table S8). Eight adults died during hospital stay, all encephalitis including three from unidentified pathogen. Six died of brain disorders and two of additional sepsis. DENV was responsible for two fatal outcomes and ZIKV for one fatal.

\section{Discussion}

Over a seven-year period, we collected 171 cases of acute CNS infection in the Caribbean island of Guadeloupe, comprising 141 encephalitis, 22 myelitis, and eight encephalomyelitis. We found that Zika 2016 outbreak had a major influence on the annual incidence of acute CNS infection, further indicating a particular tropism of ZIKV towards the CNS in children and adults. Significant adjustments in health care organization are required during epidemic zika periods. Leptospirosis was found in $6.4 \%$ of cases, and was predicted by sex (male), icterus, abdominal pain, breathing dysfunctions, increased liver enzymes and creatinine, and reduced platelet count. This is 
important for clinical practice since acute neuroleptospirosis has a good prognosis when treated early (9). Specific treatment of leptospirosis can also prevent chronic neuroleptospirosis (10).

Our study has limitations. First, due its retrospective approach, and because the annual incident rate may have been underestimated as some mild cases may not have been referred to the hospital. Second, we decided to widen the major diagnostic criteria of the International Encephalitis Consortium (11) due to the retrospective nature of clinical records and lack of information on possible alteration of mental status of certain patients. Indeed, some patients had only new onset of focal neurological findings or generalized/focal seizures mentioned in clinical records while a pathogen was detected in the CSF. Third, cross reactions between flavivirus renders the diagnosis of recent infection difficult in patients already exposed to a previous infection with a flavivirus. In our study, except during Zika outbreak, diagnosis of arboviruses was largely based on serology, as RT-PCR was not performed systematically. We think flaviviruses are implicated in a large part of the undetermined cases.

The annual incidence of acute CNS infection was tripled during the Zika outbreak (Fig. 2). Within this period (2016), proven zika-related CNS infection accounted for $40 \%$ of the cases but we suspect this percentage may largely underestimate the actual proportion of zika-related CNS encephalitis or myelitis. Indeed, the annual incidence of cases of acute CNS infection of undetermined etiology increased concurrently with the emerging of the Zika outbreak, possibly reflecting difficulties to diagnose ZIKV infection at the acute phase of neurological manifestations (12). The sudden and major increase in the number of acute CNS infections may be beyond the response capacity of the local health care system, requiring transient and rapid adjustments during Zika outbreak. During the study period, the population was exposed to a CHIKV outbreak with attack rate similar to that of ZIKV outbreak (around $60 \%$ and $50 \%$ respectively) $(13,14)$. However, this outbreak had only a minor influence on the annual incidence of acute CNS infections (Fig. 2). This further suggests that ZIKV has a particular tropism towards the CNS in addition to its well-known role in the pathogenesis of Guillain-Barré syndrome in the peripheral nervous system (8). CNS tropism of ZIKV has been largely reported during the prenatal period (15-17). In post-natal individuals, encephalitis, myelitis, encephalomyelitis represent nearly $20 \%$ of neurological manifestations of ZIKV infection $(8,18)$, and $16 \%$ of patients may have a mixed disorder involving both the central and peripheral nervous system (8). Experimental works and post-mortem analysis of affected neonates suggest that early CNS infection by ZIKV during development results in neuronal death and impairs neurodevelopment (19-21). More recently, the susceptibility of mature neuronal cells and adult human brain tissues was also demonstrated, using dedicated experimental paradigms (22).

This article is protected by copyright. All rights reserved 
In our study a pathogen was detected or highly suspected in $59 \%$ of cases. West-Nile virus (WNV) might be a candidate pathogen in some of the cases of unknown origin. This highly neurotropic flavivirus, which circulates in animals, was discovered in 2002 in Guadeloupe, particularly in horses (23). WNV serology was routinely performed only during Zika outbreak but no case was detected. This can be explained by cross-reactions (24), which can lead to a misinterpretation due to the concomitant rise of non-specific IgM for these two flaviviruses. We suggest that the detection of WNV by PCR or culture be performed in all suspected cases of encephalitis/myelitis in the Caribbean. Given the possible similarities between the two entities, infectious and autoimmune encephalitis, we cannot formally exclude that a small number of our cases of indeterminate etiology, could be autoimmune encephalitis mimicking an infectious encephalitis or being associated with infection.

Encephalitis or myelitis due to leptospirosis are extremely rare, and only isolated cases have been reported whereas aseptic meningitis is more common (9). In our series, leptospirosis represented the third cause of CNS infections, together with VZV and DENV. The incidence rate of LEPT in temperate regions has been estimated between 0.01 and $0.17 / 100000$ per year (25), as compared to $69.4 / 100000$ per year in Guadeloupe (26). We advocate that leptospirosis be tested systematically in the French West Indies and other countries of the Caribbean area, when infectious encephalitis or myelitis is suspected. Indeed delayed diagnosis and treatment can result in poor outcome during the acute phase or lead to chronic neuroleptospirosis (10). In the tropical area, the upsurge of this disorder could be partly explained by the presence of animal reservoirs other than rats (27). In our study, 10 of 11 cases concerned were men. Leptospirosis mainly affects men (28) because of their professional activities (farmers, breeders, sewer workers). It is noteworthy that in our series only three patients were employed as farmers or working with animals.

We found two rare pathogens responsible for one encephalitis and one myelitis. Aspergillus is a classical cause of meningitis, vasculitis, and brain abscess in immunosuppressed patients (29) but diffuse encephalitis as observed in our case is very unusual, particularly in immunocompetent subjects (30). Myelitis caused by infection of Angiostrongillus cantonensis is a rare condition (31) although it is the most common eosinophilic meningitis worldwide.

Given the large variety of causal agents and the high number of cases with unknown etiology, we advocate for greater access to diagnostic technics allowing direct and specific detection of multiple pathogens, particularly in tropical areas.

\section{Acknowledgments}

This article is protected by copyright. All rights reserved 
The authors thank Christophe Armand, MD, for recovering hospital database, and Yves Chaudière for his language expertise.

This work was supported by European Union and Guadeloupe Region (PO FEDER-« MALIN » 2014-2020, 2015-FED-192) and Pasteur Institute of Paris (GPF 2015 Microbes \& brain "INFECSMELL" to F.L.).

\section{References}

1. Mailles A, Vaillant V, Stahl J-P. Encéphalites infectieuses: données et limites du PMSI pour l'étude épidémiologique, France métropolitaine 2000-2002. Médecine Mal Infect. févr 2007;37(2):95-102. 2. Trevejo RT. Acute Encephalitis Hospitalizations, California, 1990-1999: Unrecognized Arboviral Encephalitis? Emerg Infect Dis. août 2004;10(8):1442-9.

3. Glaser CA, Honarmand S, Anderson LJ, Schnurr DP, Forghani B, Cossen CK, et al. Beyond Viruses: Clinical Profiles and Etiologies Associated with Encephalitis. Clin Infect Dis. 15 déc 2006;43(12):1565-77.

4. Mailles A, Stahl J. Infectious Encephalitis in France in 2007: A National Prospective Study. Clin Infect Dis. 15 déc 2009;49(12):1838-47.

5. de Ory F, Avellón A, Echevarría JE, Sánchez-Seco MP, Trallero G, Cabrerizo M, et al. Viral infections of the central nervous system in Spain: A prospective study. J Med Virol. mars 2013;85(3):554-62.

6. Olsen SJ, Campbell AP, Supawat K, Liamsuwan S, Chotpitayasunondh T, Laptikulthum S, et al. Infectious Causes of Encephalitis and Meningoencephalitis in Thailand, 2003-2005. Emerg Infect Dis [Internet]. févr 2015 [cité 5 déc 2019];21(2). Disponible sur: http://wwwnc.cdc.gov/eid/article/21/2/140291_article.htm

7. Joshi R, Mishra PK, Joshi D, Santhosh S, Parida MM, Desikan P, et al. Clinical presentation, etiology, and survival in adult acute encephalitis syndrome in rural Central India. Clin Neurol Neurosurg. sept 2013;115(9):1753-61.

8. Lannuzel A, Fergé J-L, Lobjois Q, Signate A, Rozé B, Tressières B, et al. Long-term outcome in neuroZika: When biological diagnosis matters. Neurology. 21 mai 2019;92(21):e2406-20.

9. Panicker JN. Primary neuroleptospirosis. Postgrad Med J. 1 sept 2001;77(911):589-90.

10. Wilson MR, Naccache SN, Samayoa E, Biagtan M, Bashir H, Yu G, et al. Actionable Diagnosis of Neuroleptospirosis by Next-Generation Sequencing. N Engl J Med. 19 juin 2014;370(25):2408-17.

11. Venkatesan A, Tunkel AR, Bloch KC, Lauring AS, Sejvar J, Bitnun A, et al. Case Definitions, Diagnostic Algorithms, and Priorities in Encephalitis: Consensus Statement of the International Encephalitis Consortium. Clin Infect Dis. 15 oct 2013;57(8):1114-28.

12. Aliota MT, Bassit L, Bradrick SS, Cox B, Garcia-Blanco MA, Gavegnano C, et al. Zika in the 
Americas, year 2: What have we learned? What gaps remain? A report from the Global Virus Network. Antiviral Res. août 2017;144:223-46.

13. Curlier E, Fagour L, Herrmann-Storck C, Staelen A, Breurec S, Abel S, et al. Le taux d'attaque de l'épidémie de Chikungunya dans les Antilles en 2014 a été de 60 \%. Médecine Mal Infect. juin 2017;47(4):S96-7.

14. Ledranz M, Subissi L, Cassadou S, Adelaïde Y, Noël H. Bulletin de veille sanitaire $\mathrm{N}^{\circ} 4$ Dynamique et ampleur des épidémies de Zika en Martinique et en Guadeloupe de décembre 2015 à septembre 2016. 2016.

15. Brasil P, Pereira JP, Moreira ME, Ribeiro Nogueira RM, Damasceno L, Wakimoto M, et al. Zika Virus Infection in Pregnant Women in Rio de Janeiro. N Engl J Med. 15 déc 2016;375(24):2321-34.

16. Rasmussen SA, Jamieson DJ, Honein MA, Petersen LR. Zika Virus and Birth Defects Reviewing the Evidence for Causality. N Engl J Med. 19 mai 2016;374(20):1981-7.

17. Hoen B, Schaub B, Funk AL, Ardillon V, Boullard M, Cabié A, et al. Pregnancy Outcomes after ZIKV Infection in French Territories in the Americas. N Engl J Med. 15 mars 2018;378(11):985-94.

18. da Silva IRF, Frontera JA, Bispo de Filippis AM, Nascimento OJM do, for the RIO-GBS-ZIKV Research Group. Neurologic Complications Associated With the Zika Virus in Brazilian Adults. JAMA Neurol. 1 oct 2017;74(10):1190.

19. Cugola FR, Fernandes IR, Russo FB, Freitas BC, Dias JLM, Guimarães KP, et al. The Brazilian Zika virus strain causes birth defects in experimental models. Nature. juin 2016;534(7606):267-71.

20. Martinot AJ, Abbink P, Afacan O, Prohl AK, Bronson R, Hecht JL, et al. Fetal Neuropathology in Zika Virus-Infected Pregnant Female Rhesus Monkeys. Cell. mai 2018;173(5):1111-1122.e10.

21. Azevedo RSS, Araujo MT, Oliveira CS, Filho AJM, Nunes BTD, Henriques DF, et al. Zika Virus Epidemic in Brazil. II. Post-Mortem Analyses of Neonates with Microcephaly, Stillbirths, and Miscarriage. J Clin Med. 28 nov 2018;7(12):496.

22. Figueiredo CP, Barros-Aragão FGQ, Neris RLS, Frost PS, Soares C, Souza INO, et al. Zika virus replicates in adult human brain tissue and impairs synapses and memory in mice. Nat Commun. déc 2019;10(1):3890.

23. Quirin R, Salas M, Zientara S, Zeller H, Labie J, Murri S, et al. West Nile Virus, Guadeloupe. Emerg Infect Dis. avr 2004;10(4):706-8.

24. Stettler K, Beltramello M, Espinosa DA, Graham V, Cassotta A, Bianchi S, et al. Specificity, crossreactivity, and function of antibodies elicited by Zika virus infection. Science. 19 août 2016;353(6301):823-6.

25. Pappas G, Papadimitriou P, Siozopoulou V, Christou L, Akritidis N. The globalization of leptospirosis: worldwide incidence trends. Int J Infect Dis. juill 2008;12(4):351-7.

26. Cassadou S, Rosine J, Flamand C, Escher M, Ledrans M, Bourhy P, et al. Underestimation of 
Leptospirosis Incidence in the French West Indies. Foley J, éditeur. PLoS Negl Trop Dis. 29 avr 2016;10(4):e0004668.

27. Guernier V, Lagadec E, Cordonin C, Le Minter G, Gomard Y, Pagès F, et al. Human Leptospirosis on Reunion Island, Indian Ocean: Are Rodents the (Only) Ones to Blame? Vinetz JM, éditeur. PLoS Negl Trop Dis. 13 juin 2016;10(6):e0004733.

28. Costa F, Hagan JE, Calcagno J, Kane M, Torgerson P, Martinez-Silveira MS, et al. Global Morbidity and Mortality of Leptospirosis: A Systematic Review. Small PLC, éditeur. PLoS Negl Trop Dis. 17 sept 2015;9(9):e0003898.

29. Góralska K, Blaszkowska J, Dzikowiec M. Neuroinfections caused by fungi. Infection. août 2018;46(4):443-59.

30. Kourkoumpetis TK, Desalermos A, Muhammed M, Mylonakis E. Central Nervous System Aspergillosis: A Series of 14 Cases From a General Hospital and Review of 123 Cases From the Literature. Medicine (Baltimore). nov 2012;91(6):328-36.

31. Defo AL, Lachaume N, Cuadro-Alvarez E, Maniassom C, Martin E, Njuieyon F, et al. Angiostrongylus cantonensis Infection of Central Nervous System, Guiana Shield. Emerg Infect Dis. juin 2018;24(6):1153-5.

\section{Supporting Information}

Additional Supporting Information may be found in the online version of this article:

Table S1. General characteristics of patients with acute infectious myelitis or encephalitis, 20122018.

Table S2. Pathogens identified in 59\% of cases, $2012-2018$.

Table S3. Characteristics of the 68 patients with acute CNS infection due to ZIKV, DENV, VZV, HSV, and leptospirosis, 2012-2018.

Table S4. Comparison between flaviviruses (dengue and zika) and herpes viruses (HSV, VZV, EBV).

Table S5. Factors related to zika virus.

Table S6. Detailed characteristics of the 11 patients with CNS leptospirosis, 2012-2018.

Table S7. Factors related to neuroleptospirosis. 
Table S8. Risk factors to mechanical ventilation.

\section{Figures Legends}

Figure 1. Flow chart of the selection process, 2012-2018.

Figure 2. Number of cases of acute CNS Infections, 2012-2018.

Figure 3. MRI findings in encephalitis and myelitis, 2012-2018.

(A) CHIKV myelitis in a 68 years old man: sagittal T1 Gadolinium sequence showing posterior contrast enhancement of the lumbar cord; (B) DENV myelitis in a 25 years old woman: sagittal T1 gadolinium sequence showing multiple contrast enhancement of the spinal cord (C5-C6, T3-T4, T6-T7); (C) DENV encephalitis in a 45 years old woman: Fluid-attenuated inversion recovery (FLAIR) imaging demonstrates bilateral hyperintensities in temporal lobes. (D) LEPT myelitis in a 33 years old man (patient 11, Table S6): sagittal T1 Gadolinium sequence showing multiple posterior contrast enhancement in thoracic cord (T6-T8). (E) Aspergillus sp. encephalitis in an 85 years old woman: FLAIR imaging showing multiple and bilateral hyperintensities in temporal, parietal and frontal lobes. (F) Angiostrongilus Cantonensis myelitis in a 10 months old boy: multiple contrast enhancement and swelling in the cervical and lumbar cord in a sagittal T1 Gadolinium sequence. 
Cases of acute encephalitis or myelitis
reported in hospital database $(n=259)$

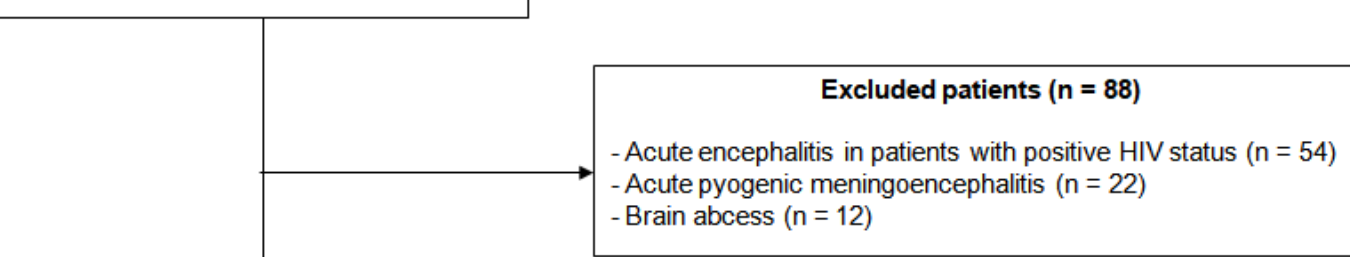

Included patients $(\mathbf{n}=171)$

- Acute infectious encephalitis $(n=141)$

- Acute infectious myelitis $(n=22)$

- Acute infectious encephalomyelitis $(n=8)$

ene_14422_f1.tif

This article is protected by copyright. All rights reserved 


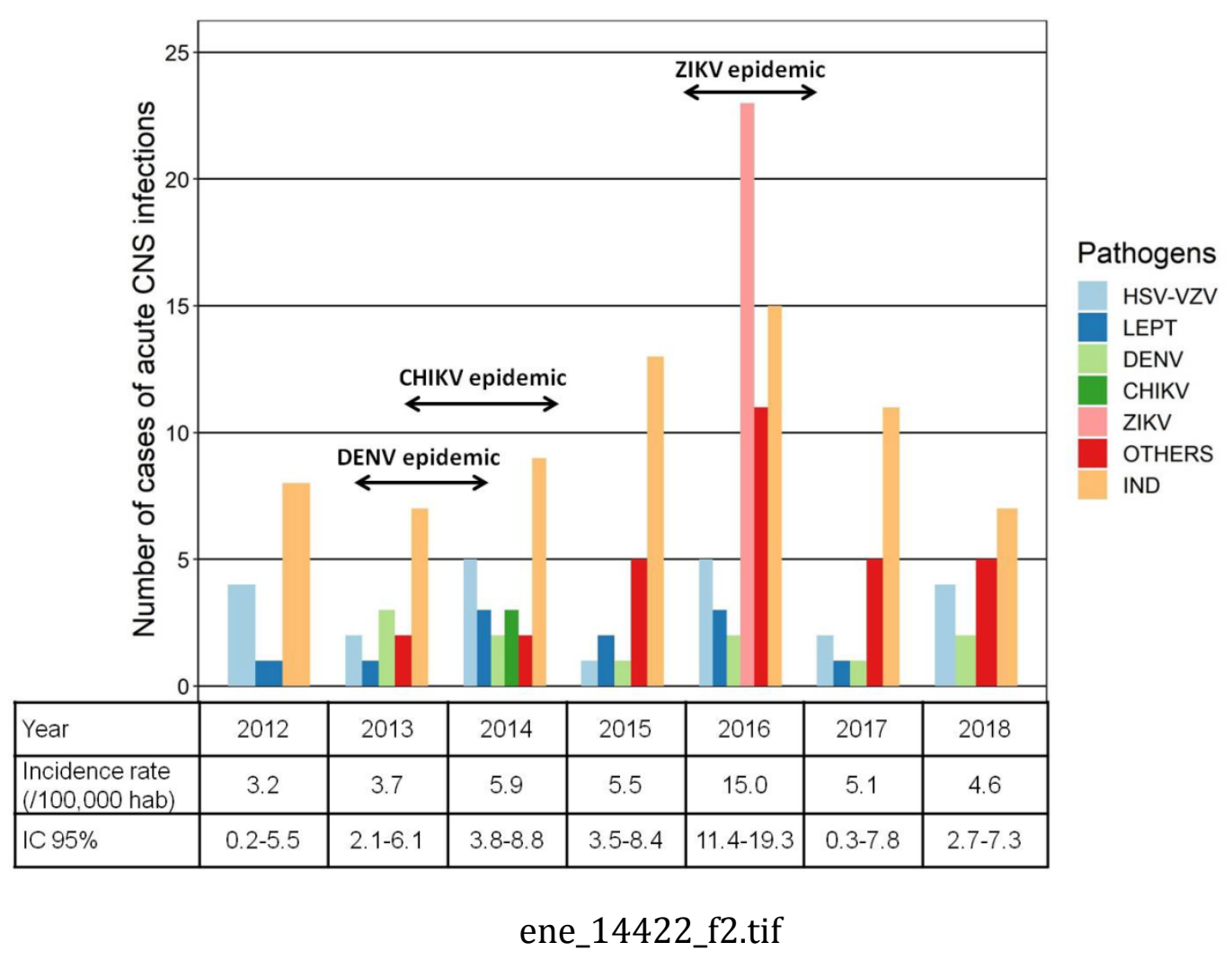

This article is protected by copyright. All rights reserved 


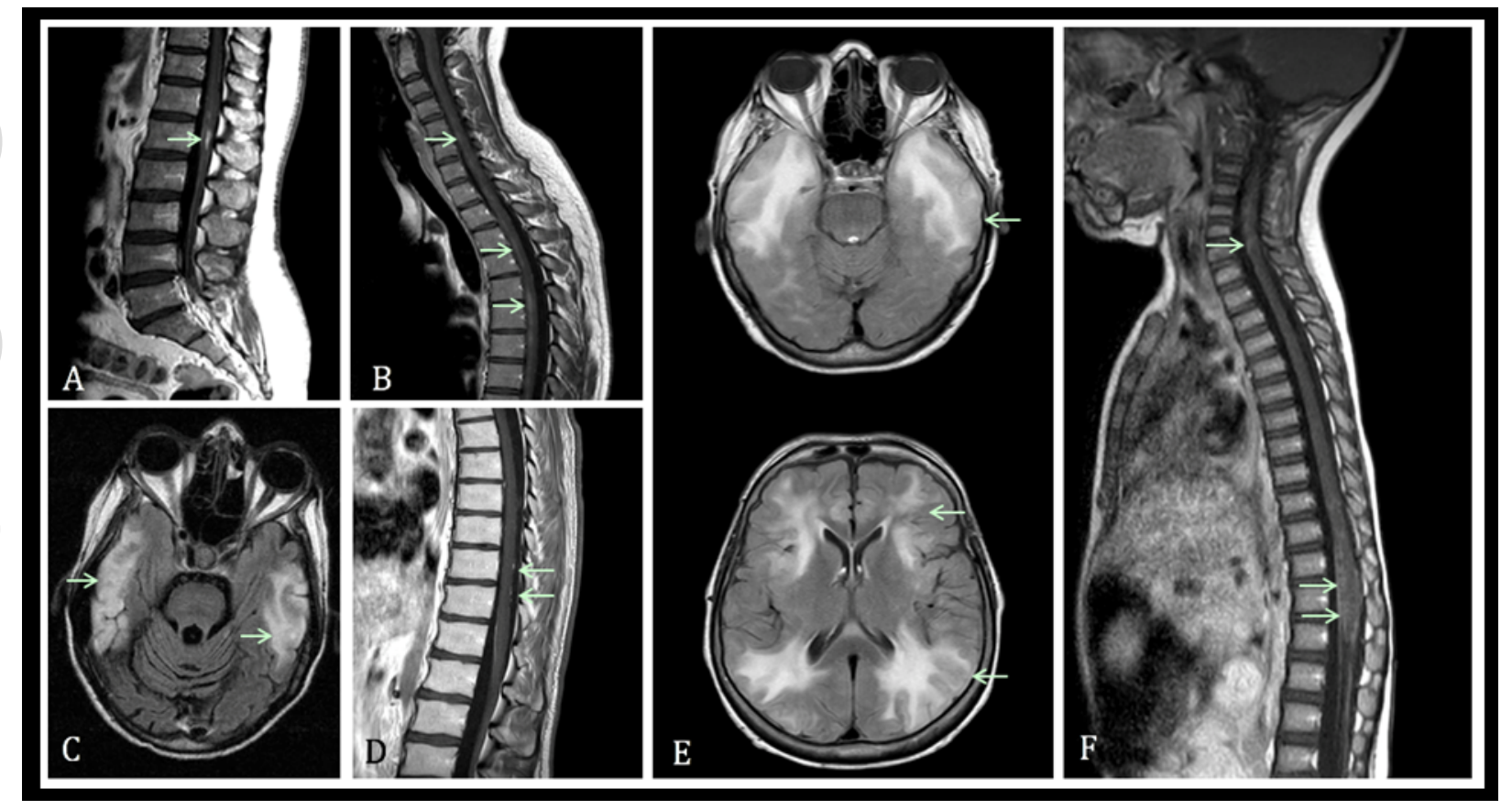

ene_14422_f3.tif 